\title{
Using waste polymers as a reliable alternative for asphalt binder modification - Performance and morphological assessment
}

\author{
Liliana M.B. Costa ${ }^{\text {a }}$, Hugo M.R.D. Silva ${ }^{\mathrm{a}, *}$, Joana Peralta ${ }^{\mathrm{b}}$, Joel R.M. Oliveira ${ }^{\mathrm{a}}$ \\ ${ }^{a}$ CTAC, Centre for Territory, Environment, and Construction, University of Minho, 4800058 Guimarães, Portugal \\ ${ }^{\mathrm{b}}$ Wacker Chemical Corporation, 6870 Tilghman Street, Allentown, PA 18106-9346, USA
}

\section{H I G H L I G H T S}

- Recycled polymers were studied as alternative to virgin SBS for binder modification.

- EVA modified binder showed similar performance to the control SBS modified binder.

- HDPE improved binder's high-temperature performance but decreased elastic recovery.

- Polymer modification enhanced binder properties, except storage stability.

-Waste plastics are an excellent alternative for more ecologic binder modification.

\section{A R T I C L E I N F O}

\section{Article history:}

Received 21 September 2018

Received in revised form 28 November 2018

Accepted 29 November 2018

\section{Keywords:}

Bitumen modification

Waste polymer

Ethylene vinyl acetate (EVA)

High-density polyethylene (HDPE)

Styrene-butadiene-styrene (SBS)

Binder characterization

Storage stability

Morphology

Rheology

\begin{abstract}
A B S T R A C T
The use of plastic wastes as an alternative to virgin polymers can be a remarkable environmentally friendly idea for road paving construction or rehabilitation. Therefore, this study aimed at assessing the potential benefits of modifying a conventional 35/50 penetration grade bitumen, with uncontaminated waste polymers (ethylene vinyl acetate and high-density polyethylene) carefully selected from plastic recycling plants. A virgin polymer (styrene-butadienestyrene) was also used as reference material since it is the polymer most commonly used for bitumen modification. The performance (physical, storage stability, and rheological properties) and morphologic characteristics of the different waste polymer modified binders were thoroughly evaluated and compared with those of the 35/50 bitumen and the virgin polymer modified binder. It was concluded that recycled EVA and virgin SBS modified binders could perform similarly, namely regarding their viscosity and rheological properties. Furthermore, EVA modified binder presented slightly better storage stability probably due to its homogeneous dispersion. The recycled HDPE modified bitumen reveals some promising physical properties (associated with rutting resistance), but it presents the worst resilience and creep recovery. The outcome of this work is the development of new asphalt binders modified with waste polymers as reliable alternatives for road paving activities due to their excellent performance, comparable to that obtained with the most commonly used virgin polymer.
\end{abstract}

() 2018 Elsevier Ltd. All rights reserved.

\section{Introduction}

The use of polymer modified bitumen in asphalt mixtures is usual in several countries, particularly to increase the service life of road pavements, and to allow the construction of thinner asphalt layers [1]. However, in some occasions, this option may double the cost of the binder [2]. At the same time, the promotion of a sustain-

\footnotetext{
* Corresponding author.

E-mail addresses: b6100@civil.uminho.pt (L.M.B. Costa), hugo@civil.uminho.pt (H.M.R.D. Silva), Joana.Peralta@wacker.com (J. Peralta), joliveira@civil.uminho.pt (J.R.M. Oliveira).
}

able development promotes the adoption of appropriate methods to protect the environment in all sectors, including in road construction [3]. Currently, high amounts of plastic waste do not follow for recycling processes, nor are they reused, and their life cycle ends by incineration or in a landfill [4]. Thus, the use of these waste polymers for bitumen modification, instead of virgin polymers, can be seen as a sustainable solution, both environmentally and economically [5].

The recycling of plastic wastes for bitumen modification in paving works has been reported in the literature, highlighting the studies carried out with high-density polyethylene (HDPE) [6-8] and ethylene vinyl acetate (EVA) $[1,9,10]$, which are the waste 
polymers used in the present work due to their better compatibility with bitumen [11]. Examples of the use of other waste polymers can also be found on previous works, namely low-density polyethylene - LDPE [12], polypropylene - PP [12,13], acrylonitrile butadiene styrene - ABS [14], polyvinyl chloride - PVC $[13,15,16]$, polyethylene terephthalate - PET [17-19]. Furthermore, recycled ground tire rubber has also been widely used [20-24].

However, some of these solutions are not suitable for bitumen modification. For instance, PVC shall not be exposed to high temperatures since it can release harmful gases [25], and PET can be used more efficiently in several other industries [26].

Several factors influence the polymer-modified binder properties. Among those factors, the polymer and bitumen characteristics, the polymer content $[27,28]$, and the production conditions (e.g., blending mixer type and time and temperature for interaction between bitumen and polymer [29]) can be highlighted.

Due to the number of factors affecting the behavior of polymer modified binders, a more advanced characterization is necessary to study this type of material. Thus, different tests are carried out to better understand the influence of those factors, namely morphological analyses (with fluorescent microscopy images) [30-32] and rheological tests at different temperatures [11,33].

The morphology and the rheological properties of the modified asphalts is the result of the mutual effects of polymer and asphalt [34]. Some researchers have also looked at the miscibility between bitumen and polymers to understand how their interaction influences the final properties of polymer modified binders [35]. However, additional work must be carried out on the use of waste polymers for binder modification in order to confirm if they behave similarly to virgin polymers.

Thus, the most innovative contribution of this paper is related to the comprehensive assessment of the changes observed in the bitumen properties that can be promoted by modification with selected waste polymers, to improve the performance of the corresponding asphalt mixtures in road pavements. In the present study, the rheological viscoelastic parameters and the morphological structure of different polymer modified binders (both with virgin and recycled polymers) are evaluated together with their physical characteristics, to find some fundamental reasons why these new solutions and the reference polymer modified binder can perform identically. The relative performance of the binders modified with waste polymers was compared to that of the binder modified with the most commonly used virgin polymer so that practitioners can select their most appropriate applications in roadworks.

\section{Materials and methods}

\subsection{Materials}

As mentioned above, EVA and HDPE waste polymers were selected as those with the highest potential for use in asphalt mixtures. However, styrenebutadienestyrene (SBS) is the elastomer most used for bitumen modification among the commercial polymers [36], followed by the plastomer EVA [2]. Although an effort has been made to find both materials in a recycled nature, it was only possible to acquire recycled EVA. Since there was no recycled SBS available, a virgin SBS was used as reference material for the binder modification study.

Both virgin and recycled polymers were obtained from the supplier as crumbs with a maximum particle size of approximately $4.0 \mathrm{~mm}$. Chen et al. [37] showed that it is difficult to ensure adequate dispersion of elastomers, such as SBS, with this particle size using a low shear mixer. Other polymers with high fusion temperatures, like HDPE, may show the same problem. Thus, to achieve a homogeneous distribution of the SBS and HDPE polymers in the bitumen, it was decided to reduce their crumbs to a powder passing a $0.45 \mathrm{~mm}$ sieve mesh. The polymeric materials were frozen with liquid nitrogen and then milled to achieve that particle size. As explained in Section 3, an adequate dispersion of EVA in the bitumen is quick and easy to reach, even without reducing the initial EVA particle size.
A 35/50 pen grade bitumen, commonly used in Portugal, was used for binder modification, with penetration and softening point values of $46 \times 0.1 \mathrm{~mm}$ and $52{ }^{\circ} \mathrm{C}$, respectively.

\subsection{Methods}

After assessing the melting behavior of the polymer and plastic wastes (recycled HDPE and EVA, and virgin SBS) by calorimetry tests, they were used to produce binders with a percentage of $5 \%$ by weight of bitumen, in a low shear mixer (600 rpm) for $1 \mathrm{~h}$ at $180^{\circ} \mathrm{C}$. These conditions assured a satisfying polymer dispersion in the binder during the laboratory works.

The modified bitumens performance was evaluated by several characterization tests, such as physical/mechanistic-empirical characterization [38] storage stability evaluation [39], morphologic structure analysis [40] rheological assessment [41] including creep-recovery tests.

\subsubsection{Calorimetry tests}

Differential scanning calorimetry (DSC) experiments were carried out to assess the thermal behavior of the polymers studied in this work and to identify their glassy, rubbery or liquid states at different temperatures when dispersed in the modified bitumen. The DSC tests were carried out on DSC-Netzsch equipment using three replicate samples, at a heating rate of $10^{\circ} \mathrm{C} / \mathrm{min}$, from the temperature of $-40{ }^{\circ} \mathrm{C}$ to $160{ }^{\circ} \mathrm{C}$.

\subsubsection{Physical characterization and storage stability}

The physical characterization of bitumens (EN 12591 standard) includes the evaluation of their softening point or ring and ball (R\&B) temperature (EN 1427), and their penetration at $25^{\circ} \mathrm{C}$ (EN 1426). The asphalt binder characterization also comprises resilience tests (EN 13880-3), especially for polymer-modified binders. Additionally, storage stability tests were carried out (EN 13399) to evaluate the possibility of storing the modified binders at high temperatures under specific conditions.

The modified binders may have high viscosity and reduced workability, requiring an evaluation of its dynamic viscosity at production/mixing temperatures (EN 13302).

\subsubsection{Morphologic structure}

The term morphology is often used to describe the microstructure of the interaction between the bitumen and polymers [37]. The morphologic structure was analyzed by fluorescence microscopy under an Olympus BH2-RFCA microscope using three replicate samples. The bitumen comprises two main fractions, the asphaltenes, and the maltenes. Polymers swell due to the absorption of the maltenes, which are transparent, apparently increasing the volume of the polymer-rich phase [30]. Under the fluorescent microscopy, the polymers structures appear as bright objects against a dark (bitumen) background [42].

For sample preparation, a small droplet of asphalt binder was placed in a heated microscope glass and spread with the help of a hot spatula to form a thin film.

\subsubsection{Rheological analysis}

Bitumen samples were poured into molds before the rheological tests. The rheometer used in this test was the TA instruments AGR2 (rotational) which operates under stress control. The test was performed using the plate-plate geometry (40 $\mathrm{mm}$ diameter and $1 \mathrm{~mm}$ gap).

In dynamic measurements, the temperature was varied from 30 to $80^{\circ} \mathrm{C}$ for the less viscous binders (modified with HDPE and EVA) and from 45 to $90{ }^{\circ} \mathrm{C}$ for the more viscous one (modified with SBS). The choice of temperatures was adjusted to the behavior of the material, in order to be adequate for the geometry used. A frequency range of $100-0.01 \mathrm{~Hz}$ was applied to construct the master curves of the material dynamic behavior. The applied strain was kept within the linear viscoelastic region.

The time-temperature superposition principle (TTSP) is valid for rheologically simple materials and is used to build master curves for the selected reference temperature $\left(60^{\circ} \mathrm{C}\right.$ ) by shifting the frequency sweep test results (obtained at different temperatures) along the horizontal axis, until reaching a continuous curve [43]. The Williams-Landel-Ferry (WLF) empirical equation (Eq. (1)) was used in this work to apply the TTSP to the experimental data. In that equation, $T$ is the variable test temperature, $T_{r}$ is a reference temperature of $60^{\circ} \mathrm{C}$ chosen to construct the master curve, and $C_{1}, C_{2}$ are empirical constants adjusted to fit the values of the parameter $a_{T}$ using the experimental data obtained in the rheology tests.

$\log \left(\alpha_{T}\right)=\frac{-C_{1}\left(T-T_{r}\right)}{C_{2}+\left(T-T_{r}\right)}$

The previous equation was used to fit values of the shift factor $\mathrm{a}_{\mathrm{T}}$ against test temperature. Then, those values are used to horizontally shift the rheology data when they are plotted vs. frequency in double logarithmic scale so that the data sets obtained at different temperatures $\mathrm{T}$ can be superposed at the reference temperature $\mathrm{T}_{\mathrm{r}}$. 


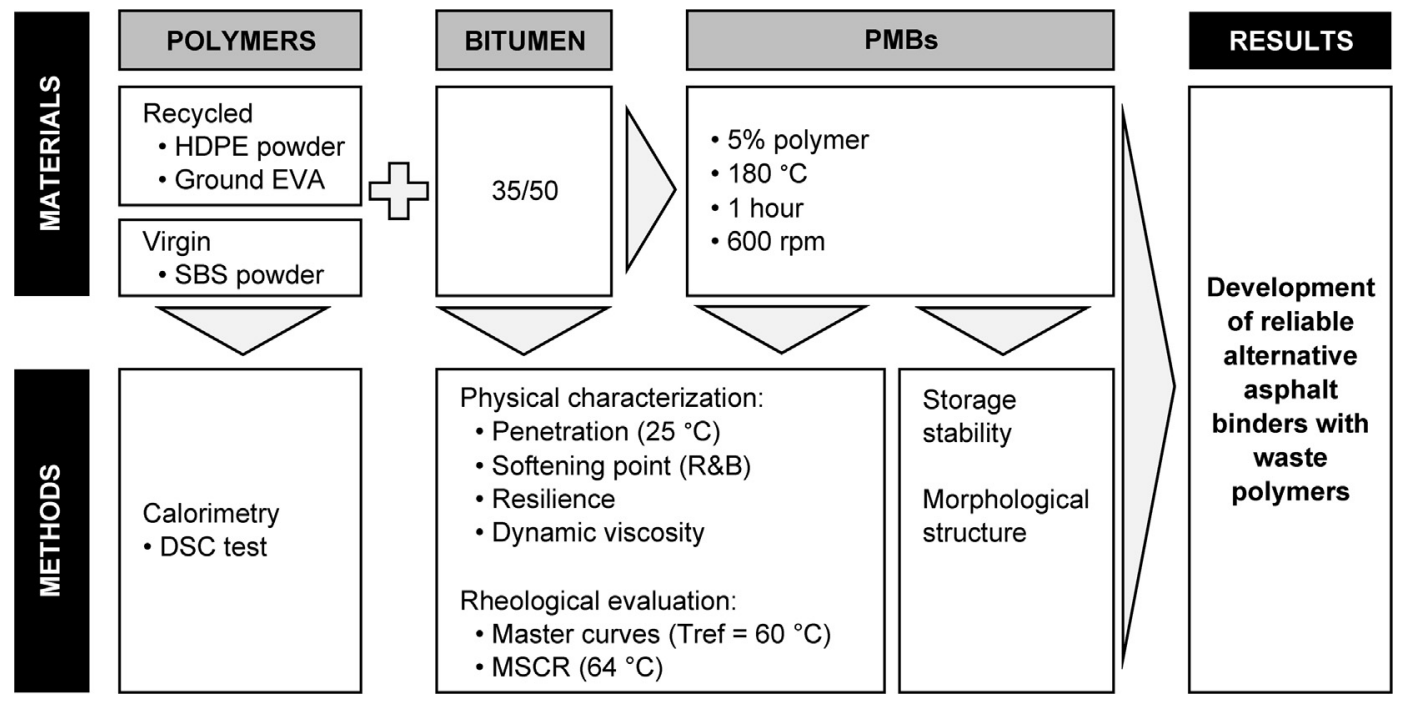

Fig. 1. Schematic representation of research outline used in this work.

Then, multiple stress creep recovery (MSCR) tests were carried out, at the most common high-temperature performance grade $\left(64^{\circ} \mathrm{C}\right)$ in Portugal, in order to determine the creep and creep-recovery response, and the corresponding stress dependence of the studied asphalt binders. This test can be related to the permanent deformation of asphalt materials in road pavements under repeated load. The creep behavior was characterized using a StressTech HR rheometer, also with a plateplate geometry ( $40 \mathrm{~mm}$ diameter and $1 \mathrm{~mm}$ gap).

The most commonly accepted MSCR test procedure [44] uses a $1 \mathrm{~s}$ creep loading with $9 \mathrm{~s}$ recovery over the multiple stress levels of $25,50,100,200,400,800,1600$, $3200,6400,12,800$ and $25600 \mathrm{~Pa}$, applying 10 cycles at each stress level (although the stress level was limited to $3200 \mathrm{~Pa}$ in this work). The average non-recovered strain, for the ten creep and recovery cycles, is then divided by the applied stress for those cycles, yielding the non-recoverable compliance $\mathrm{J}_{\mathrm{nr}}$ (AASHTO TP 70-11).

\subsection{Research outline}

In order to summarize the relationship between the materials and analysis methods involved in this paper, the research outline followed in this work is schematically represented in Fig. 1.

\section{Results and discussion}

\subsection{Characterization of the polymers}

The melting point ( $\mathrm{Tm}$ ) temperature of plastic wastes is critical due to the influence on their compatibility with the asphalt binder and on the modification success $[7,8]$. These results were obtained in the DSC tests, whose thermograms are shown in Fig. 2.

Those thermograms show that both recycled HDPE and EVA melt below the modified binder production temperature $\left(180^{\circ} \mathrm{C}\right)$, which validates the selection of that temperature for this study. The virgin SBS is an amorphous elastomer because it does not pre-

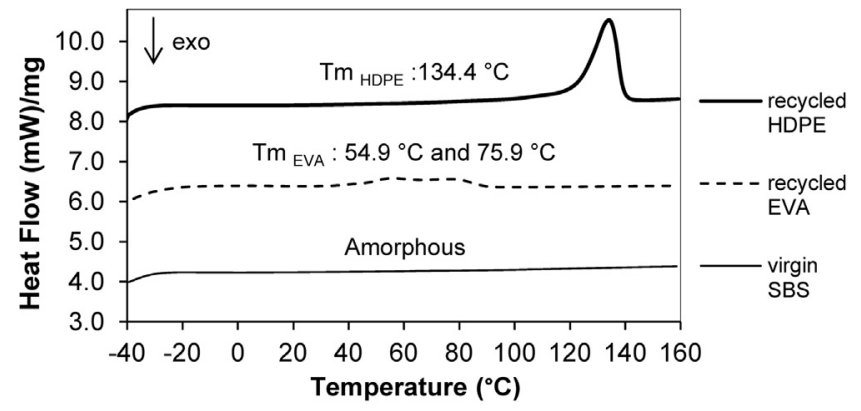

Fig. 2. DSC thermograms of recycled HDPE and EVA and virgin SBS. sent a melting temperature. Therefore, the dispersion of SBS into the bitumen is expected to be more difficult, which justified the reduction of the SBS particles into a powder of simple dispersion. The recycled HDPE crumbs were also reduced to powder to improve their dispersion into the bitumen because the HDPE melting point $\left(\approx 134^{\circ} \mathrm{C}\right)$ is relatively close to the production temperature of the modified binders. In contrast, the recycled EVA particles maintained their initial size for binder modification, because the EVA liquid state occurs at a relatively low temperature $\left(\approx 76{ }^{\circ} \mathrm{C}\right)$ and these polymer particles become easy to disperse into the hot bitumen.

\subsection{Asphalt binder characterization}

First, several polymer modified binders were manufactured and their basic properties evaluated, including the softening point temperature, the penetration value and the resilience (Fig. 3). Then, Fig. 4 presents the dynamic viscosity results at different temperatures.

The storage stability of the polymer modified binders is presented in Fig. 5, and the statistical analysis of those results is presented in Fig. 6. Furthermore, the study of the morphologic structure of those binders can be seen in Fig. 7.

The main rheological parameters obtained for the base bitumen and modified binders, namely the complex modulus $\left(\mathrm{G}^{*}\right)$ and phase angle $(\delta)$, are respectively shown in Figs. 8 and 9. Finally, and the non-recoverable creep compliance values $\left(\mathrm{J}_{\mathrm{nr}}\right)$ obtained from the MSCR test are presented in Figs. 10 and 11.

\subsubsection{Physical characterization}

Rutting of asphalt mixtures is considered to be one of the main pavement distress modes, and it can also induce the development of other pavement problems. According to the EN 1427 standard, the softening point or R\&B temperature of an asphalt binder can give important indications about the propensity of the resulting mixture to develop permanent deformations in road pavements.

According to the EN 1426 standard, penetration is the physical property of asphalt binders most closely related with the fatigue cracking resistance and stiffness modulus of the resultant mixtures. Fig. 3 presents the penetration values results for the base bitumen and binders modified with virgin SBS powder (SBS(V)p), granulated recycled EVA (EVA(R)gr), and recycled HDPE powder (HDPE(R)p). 


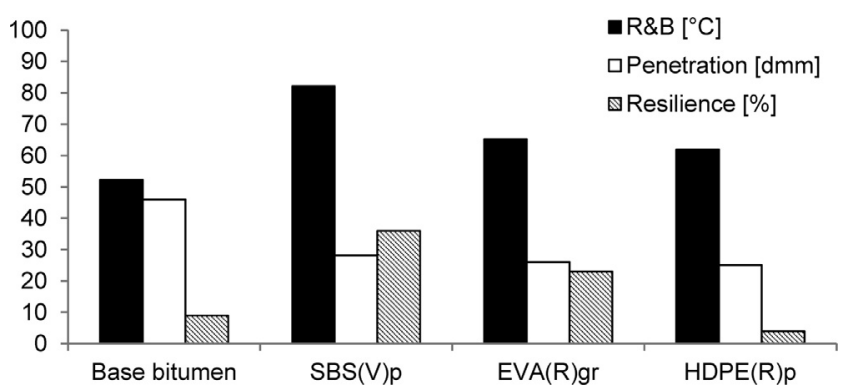

Fig. 3. Physical properties of the different asphalt binders.

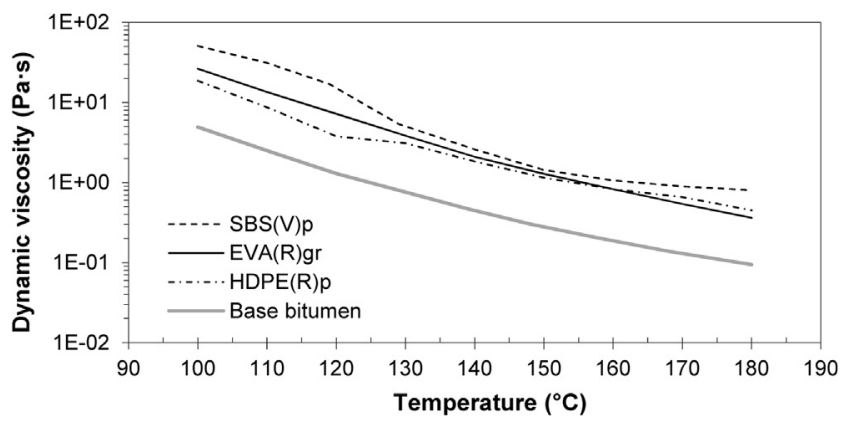

Fig. 4. Dynamic viscosity results of the asphalt binders.

The resilience test (EN 13880-3 standard) evaluates the binder capacity to recover its initial shape after an imposed deformation/load applied during a short period. This test can be associated both with the rutting and the fatigue cracking resistance of the

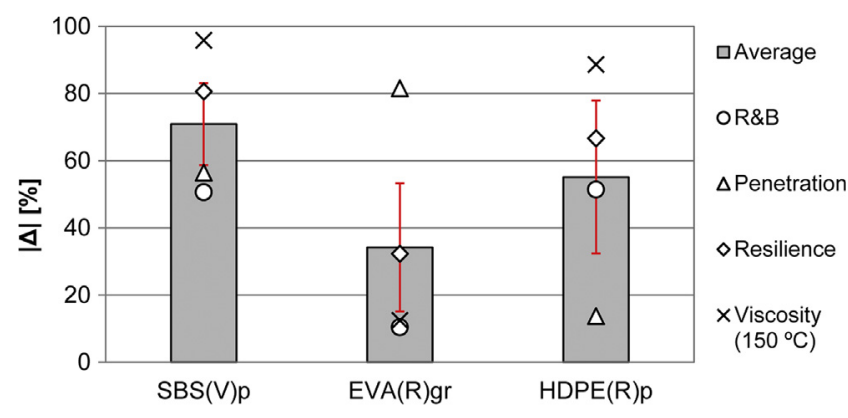

Fig. 6. Storage stability of the modified asphalt binders selected for this study.

asphalt mixtures. Fig. 3 shows the resilience test results obtained in this work.

As expected, the polymer modification (virgin SBS and EVA and HDPE plastic wastes) increased the base bitumen softening point temperature. The higher increase of that property was obtained for the virgin SBS modified binder ( $\approx 58 \%$ ), followed by the recycled EVA ( $\approx 25 \%)$, and recycled HDPE ( $\approx 19 \%)$ modified binders. According to these results, the modified binder with the best rut resistance performance is the SBS modified binder, but all modified binders presented very high R\&B temperatures (higher than $60^{\circ} \mathrm{C}$ ).

Despite the good permanent deformation resistance of the binders after modification, some other significant pavement distresses related to the binder properties need to be addressed, namely those associated with fatigue cracking resistance and stiffness of asphalt mixtures in the pavement at service temperatures.

Regarding the penetration test results, it is evident that all polymeric materials reduced the base bitumen penetration value. The polymer with higher influence in the penetration value is the

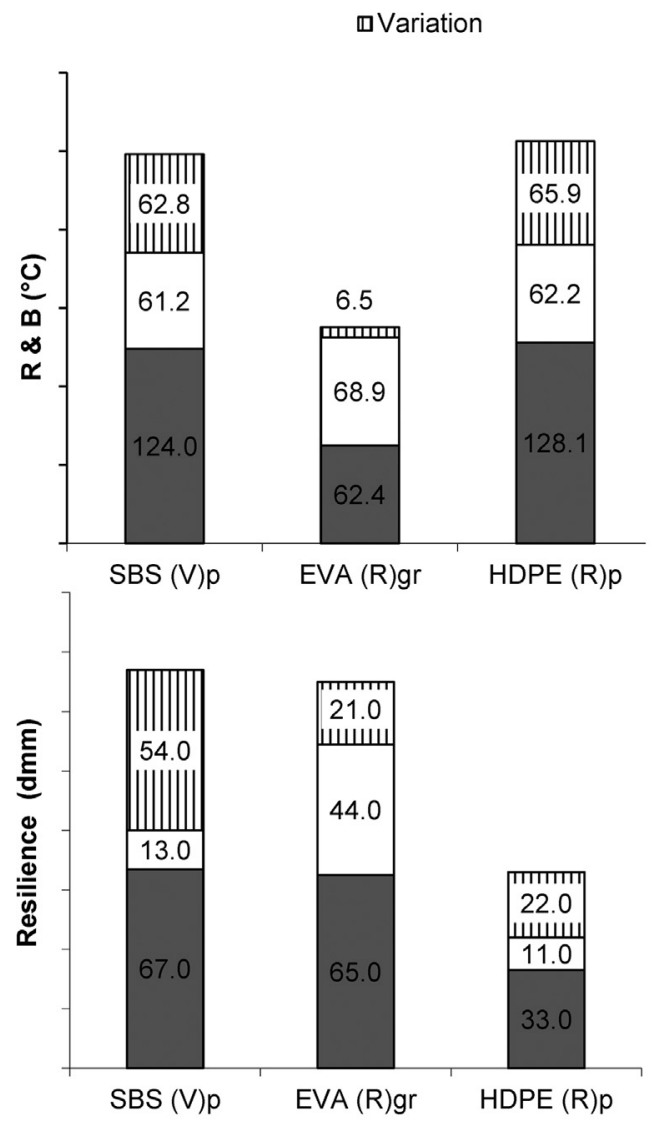

口Base $\quad$ aTop

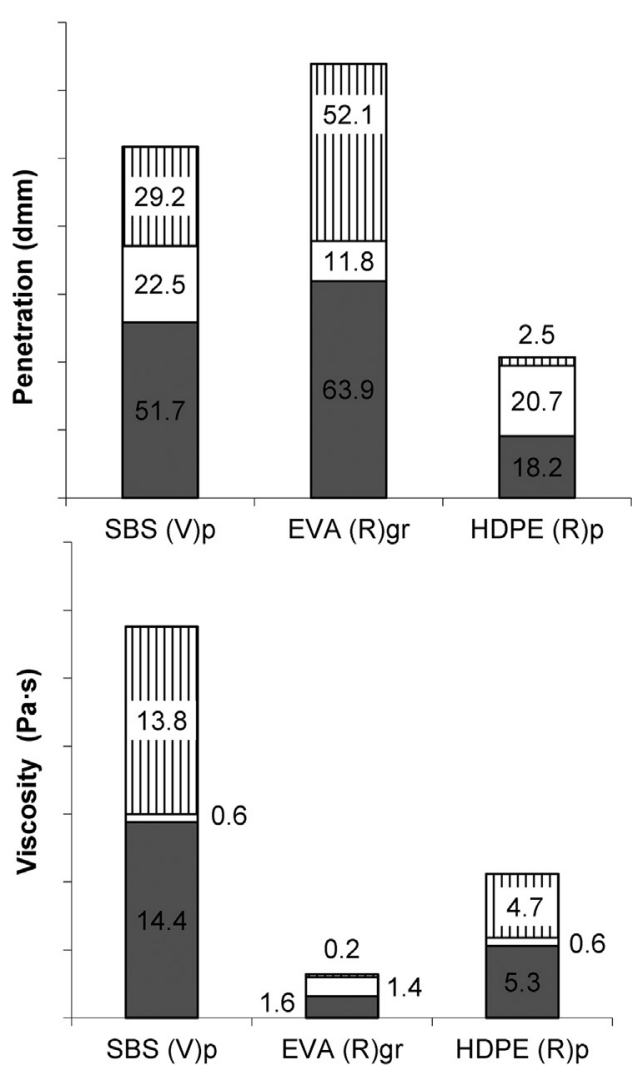

Fig. 5. Modified binders storage stability after three days at $180^{\circ} \mathrm{C}$. 

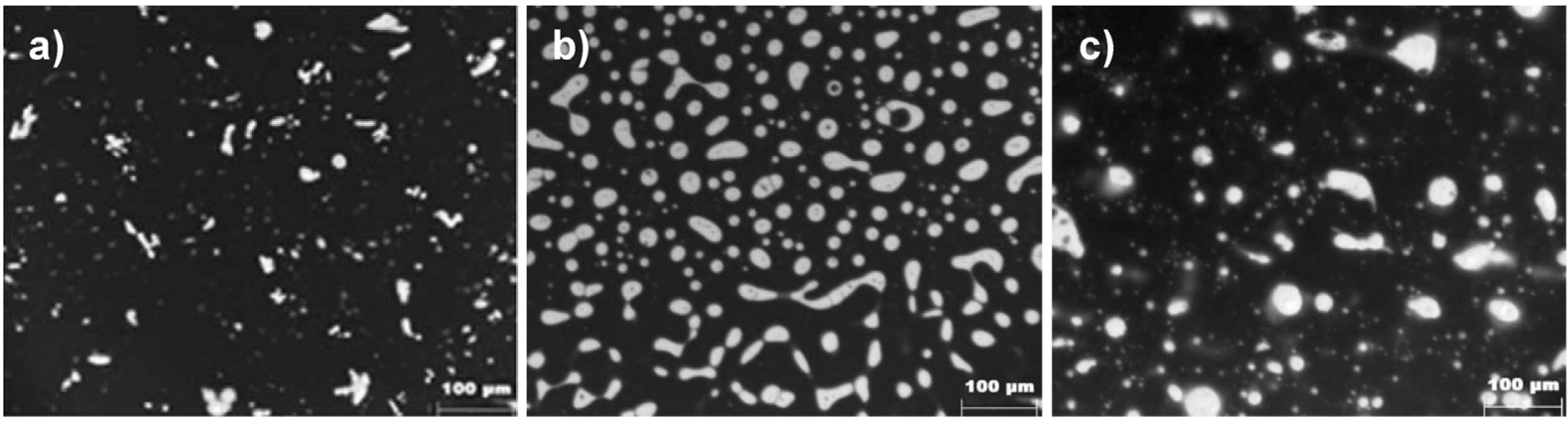

Fig. 7. Fluorescence micrographs of bitumen modified with a) SBS, b) EVA and c) HDPE.

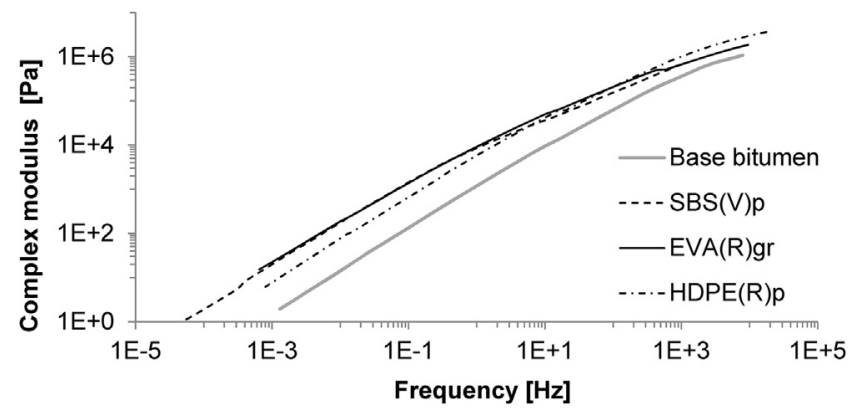

Fig. 8. Master curves of the studied binders complex modulus $\left(\mathrm{T}_{\mathrm{REF}}=60^{\circ} \mathrm{C}\right)$.

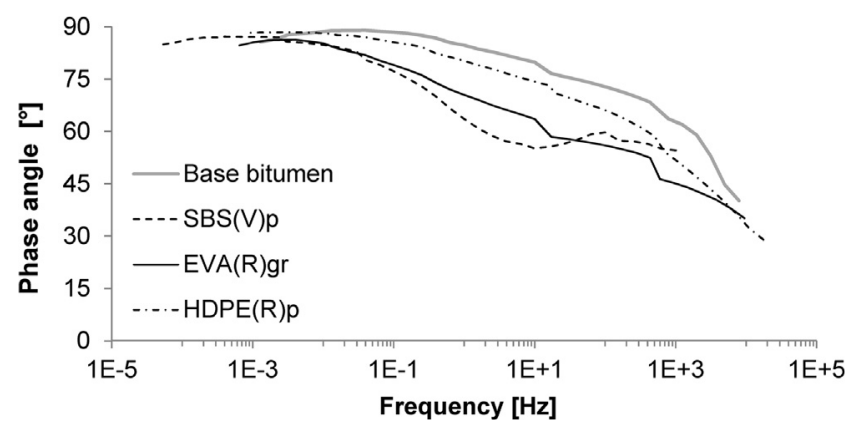

Fig. 9. Master curves of the studied binders phase angle $\left(T_{\text {REF }}=60^{\circ} \mathrm{C}\right)$.

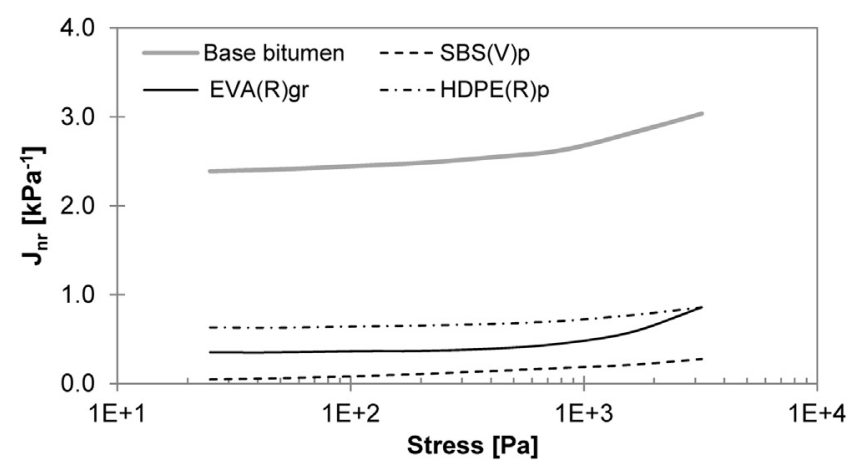

Fig. 10. Non-recoverable creep compliance $\left(J_{n r}\right)$ obtained from MSCR tests at $64{ }^{\circ} \mathrm{C}$.

recycled HDPE ( $\approx 46 \%)$, followed by the recycled EVA ( $\approx 43 \%)$, and the virgin SBS ( $\approx 39 \%)$. The higher stiffness of polymers can explain the low penetration values of the polymer modified binders at $25^{\circ} \mathrm{C}$.

Typically, a higher penetration value is related to a lower stiffness modulus and higher fatigue cracking resistance of the mix-

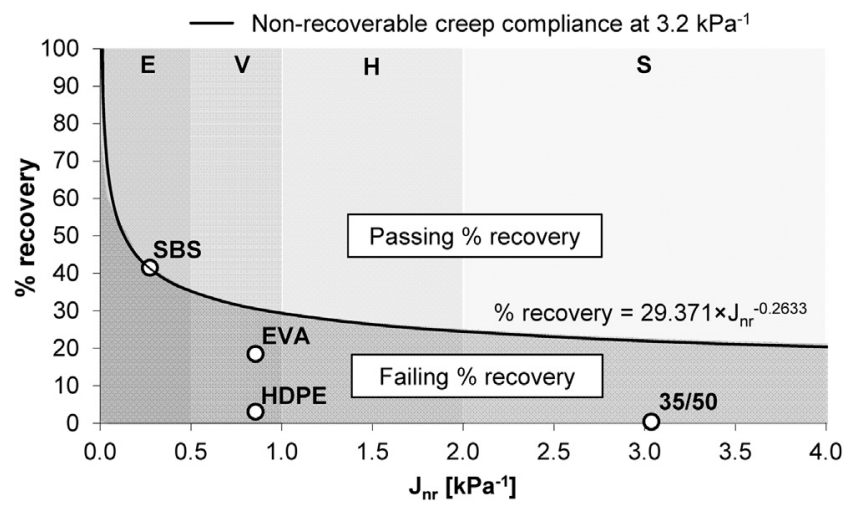

Fig. 11. Non-recovery creep compliance versus percent recovery.

tures. Therefore, among the polymer modified binders studied, the SBS modified bitumen is likely to have the best fatigue cracking performance, whereas the HDPE modified binder is expected to present the highest stiffness modulus.

The previous two set of results (R\&B temperature and penetration value) partially showed contradictory results. In fact, in the one hand, it looks like the polymer modified binders increase the rutting resistance performance, and on the other hand, they seem to reduce the fatigue cracking performance of the unmodified bitumen. However, since some polymer modified binders have a significant elastic recovery after each loading cycle (mainly those modified with elastomers, as it will be observed in the resilience test results), the corresponding fatigue cracking resistance can be significantly increased even though these binders have reduced penetration values.

Concerning the resilience test results, the polymer modified binders with the best performance are those modified with elastomers, such as the virgin SBS, followed by the recycled EVA. The HDPE modified binder presents the lowest resilience value because this polymer modified binder has no elastic recovery properties and it is stiffer than the unmodified bitumen at the testing temperature $\left(25^{\circ} \mathrm{C}\right)$.

The resilience test gives some additional information about the binders' performance, showing that those with elastomers (SBS and EVA) perform better than the unmodified bitumen regarding fatigue cracking and rutting resistance, but the modification with HDPE (plastomer) decreases the fatigue cracking performance. Possible solutions to overcome the lower fatigue cracking resistance of this binder can include a softer base bitumen or lower amounts of HDPE for polymer binder modification.

The last property evaluated in this part of the study was the viscosity (EN 13302) at different high temperatures. This property is especially important in asphalt binders, as they need to have a sufficiently low viscosity to coat the aggregates during the mixing 
phase and to provide workability to the mixtures during compaction. The binder viscosity values at high temperatures are also essential to define pumping and mixing conditions that are critical for asphalt production and transportation, as well as for pavement construction. Fig. 4 presents the viscosity test results at different temperatures.

A viscosity value between 0.2 and $0.3 \mathrm{~Pa} \cdot \mathrm{s}$ is usually recommended for asphalt mixing. Consequently, the binders studied in this work should be mixed at temperatures higher than $180^{\circ} \mathrm{C}$. Nevertheless, the binders with recycled HDPE and EVA show lower viscosity than that of the binder with virgin SBS, which is as an advantage of the modification with those recycled polymers (better workability).

\subsubsection{Storage stability evaluation of the polymer modified binders}

For modified binders, adequate storage stability is seen as a clear technological and economic advantage, namely because specific equipment for bitumen modification becomes no longer needed next to the asphalt batch plant. According to EN 13399, the modified binder is stable when the difference between the physical properties of the upper and lower parts of the sample, after storage under certain conditions, are lower than those specified $\left(5^{\circ} \mathrm{C}\right.$ for R\&B and $9 \times 0.1 \mathrm{~mm}$ for penetration [45]). Fig. 5 presents the variation of the physical properties results between the top and the bottom/base parts of the stored samples of each modified binder studied in this work.

The results of this test show that, according to EN13399, all the binders selected for this study are not stable to storage, because the top and bottom samples showed differences higher than the acceptable values. Nevertheless, in order to assess which modified binder is more stable to storage, the results were further analyzed by computing the average of percentage variation of the different properties for each modified binder (Fig. 6).

Based on the error bars, a statistical difference between the binders with EVA and SBS can be observed regarding their storage stability, while it is difficult to distinguish between the HDPE and the other modified binders. Generally, it seems that the EVA modified binder is less susceptible to phase separation than the other binders evaluated in the study, namely the control SBS modified binder, which is an advantage of this solution supporting further development of this binder and its future use in road pavements.

\subsubsection{Morphologic structure analysis of the polymer modified binders}

The effect of the morphological structure of the polymer modified binders on the phase separation after storage shall be better understood to produce stable binders. Thus, the polymer dispersion in the bitumen was evaluated using fluorescence microscopy images of the studied binders (Fig. 7).

Although the modified binders have the same amount of each polymer, the fluorescence micrographs show that the polymers dispersion in the bitumen varies among them. A more homogeneous dispersion was obtained with recycled EVA, which is compliant with the storage stability results. In this case, by using only $5 \%$ of EVA, it was nearly reached the equilibrium between the polymer and bitumen phases. Since the base bitumen and the polymer contents are the same for all the modified binders, the differences on the morphology might be a function of the swelling potential of the polymers. The different morphology of the polymer modified binders will undoubtedly be reflected in different rheological characteristics of the modified binders.

\subsubsection{Rheological evaluation}

Based on the time-temperature superposition principle, the master curves for the complex modulus (Fig. 8) and phase angle (Fig. 9) of the several binders were drawn.
Regarding the rheological behavior of the modified binders, the polymer addition increases the binder stiffness, which improves its high service temperature performance. The stiffness of all binders is dependent on the frequency. The binders that showed higher stiffness at low temperatures or high frequencies were modified with recycled HDPE, succeeded by EVA and virgin SBS. At high temperatures (or low frequencies), the binder produced with virgin SBS showed higher stiffness, followed very closely by recycled EVA and finally the recycled HDPE. The binder produced with recycled EVA showed the best complex modulus behavior among the recycled materials, being rheologically similar to the SBS modified binder.

Regarding the phase angle results, a lower phase angle corresponds to a higher elastic response of the binder. The recycled EVA modified binder showed a higher elastic response at low temperatures (high frequencies). At high temperatures (low frequencies), the lower phase angle was presented by SBS, followed very closely by recycled EVA, and then by recycled HDPE. Generally, the recycled EVA modified binder can be seen as an excellent alternative because its rheological behavior is similar to that of the control virgin SBS modified binder.

Finally, Fig. 10 shows the MSCR test results, according to the protocol defined in AASHTO TP $70-11$, at $64^{\circ} \mathrm{C}$, for the base and modified bitumens studied in this work.

The virgin SBS modified binder outperformed the others regarding this parameter, while the base bitumen exhibited the worst performance. Among the modified asphalt binders produced with recycled materials, the recycled EVA modified binder showed the best result, which encourages its future use as an alternative environmentally-friend solution for road paving works. Nevertheless, the modified binder produced with recycled HDPE presents a promising result in this test.

In order to provide a mean to determine the presence of elastic response and the stress dependence of the polymer modified and unmodified asphalt binders, the AASHTO TP 70-11 protocol uses the value of percentage recovery (Fig. 11) for further evaluation of MSCR results. An asphalt modified binder can be seen as modified with an acceptable elastomeric polymer only when the results of Fig. 11 (\% recovery vs $\mathrm{J}_{\mathrm{nr}}$ ) are above the line defined by the equation $\%$ recovery $=29.371 \times \mathrm{J}_{\mathrm{nr}}^{-0.2633}$.

The SBS modified bitumen has an adequate elastic response, meaning that the elastomeric polymer is working. The other asphalt binders do not have the necessary creep recovery behavior according to this specification. The thermoplastic nature of HDPE justifies this results for the recycled HDPE modified bitumen. The EVA modified binder approaches the acceptance criteria, due to the EVA elastomeric properties, but this binder needs a few additional inputs to pass this standard condition. Probably, a more substantial amount of recycled EVA may be needed to design an alternative recycled EVA modified binder similar to the control one (with virgin SBS).

By using the AASHTO MP 19-10 specification, a complementary analysis (Fig. 10) was carried out to characterize the performancegrade of the binders using the multiple stress creep-recovery test. This specification defines four traffic loading levels as " $E$ " for the extremely high traffic, "V" for very high traffic, " $H$ " for high traffic and " $\mathrm{S}$ " for standard traffic.

According to the traffic levels, bitumen modification with the recycled EVA and HDPE polymers increases his performance from a standard traffic level to a very high traffic level. The SBS modified bitumen is adequate for extremely high traffic level. Thus, the modification with all polymers significantly increase the performance-grade of the unmodified bitumen, but the recycled polymers (EVA and HDPE) are slightly less efficient than the control polymer (virgin SBS). 


\section{Conclusions}

The SBS modified binder was used as a control material because SBS is the virgin polymer most used for bitumen modification. Actually, it stands out in several physical properties, such as higher softening point and resilience, and lower penetration. However, the performance of the recycled EVA modified binder is often similar to (and occasionally better than) that of the binder produced with virgin SBS. The conclusions indicated by the physical characterization are attested by the morphological structure and the rheology of the modified binders. EVA and SBS modified binders have similar viscosity and rheological properties. In comparison to SBS modification, the EVA modified bitumen showed lower viscosity at high temperatures, which can improve the workability during the mixture and compaction phases, and presented slightly better storage stability at high temperatures probably due to its homogeneous dispersion.

The recycled HDPE modified bitumen reveals some promising results in the penetration (associated to asphalt mixtures stiffness) and softening point (associated to asphalt mixtures rutting resistance) tests, and this recycled polymer is cheaper and easier to obtain. However, this HDPE modified binder globally presents the worst resilience and creep recovery (MSCR test) results, apparently reducing the fatigue cracking performance of corresponding mixtures. In contrast, the binders with recycled EVA and virgin SBS show excellent results related to creep and elastic recovery.

The present study allowed concluding that the waste plastics are an exciting alternative for the production of more ecologic and, probably, more economic polymer modified binders. Taking into account the physical, morphological and rheological characterization, the recycled EVA modified binder is the alternative solution with the best performance when using recycled polymers.

\section{Conflict of interest}

The authors of this manuscript wish to confirm that there are no known conflicts of interest associated with this publication and there has been no significant financial support for this work that could have influenced its outcome.

\section{Acknowledgments}

The authors must acknowledge the material and financial support given by some institutions. European Regional Development Fund (ERDF), European Union (EU) funds funded this work through the Operational Competitiveness Program (COMPETE 2020). National funds from the Portuguese Foundation for Science and Technology (FCT), Portugal also supported this work in the scope of the strategic project UID/ECI/04047/2013. Thanks are also due to Gintegral (supplier of recycled polymers) and CEPSA (supplier of base bitumen).

\section{References}

[1] U. Isacsson, X. Lu, Testing and appraisal of polymer modified road bitumensstate of the art, Mater. Struct. 28 (3) (1995) 139-159.

[2] Y. Becker, M.P. Méndez, Y. Rodríguez, Polymer modified asphalt, Vision Tecnologia 9 (1) (2001) 39-50.

[3] Peng C-l, D.E. Scorpio, C.J. Kibert, Strategies for successful construction and demolition waste recycling operations, Constr. Manage. Econ. 15 (1) (1997) 49-58.

[4] E. Spalvins, B. Dubey, T. Townsend, Impact of electronic waste disposal on lead concentrations in landfill leachate, Environ. Sci. Technol. 42 (19) (2008) $7452-$ 7458.

[5] F. Gschösser, H. Wallbaum, Life cycle assessment of representative swiss road pavements for national roads with an accompanying life cycle cost analysis, Sci. Technol. 47 (15) (2013) 8453-8461.

[6] S. Hınıslıoğlu, E. Ağar, Use of waste high density polyethylene as bitumen modifier in asphalt concrete mix, Mater. Lett. 58 (3-4) (2004) 267-271.
[7] S.R.M. Fernandes, H.M.R.D. Silva, J.R.M. Oliveira, Recycled stone mastic asphalt mixtures incorporating high rates of waste materials, Constr. Build. Mater. 187 (2018) 1-13.

[8] S.R.M. Fernandes, H.M.R.D. Silva, J.R.M. Oliveira, Developing enhanced modified bitumens with waste engine oil products combined with polymers, Constr. Build. Mater. 160 (2018) 714-724.

[9] M. García-Morales, P. Partal, F.J. Navarro, F. Martmez-Boza, C. Gallegos, N. González, et al., Viscous properties and microstructure of recycled EVA modified bitumen, Fuel 83 (1) (2004) 31-38.

[10] M. Ranieri, L. Costa, J.R.M. Oliveira, H.M.R.D. Silva, C. Celauro, Asphalt surface mixtures with improved performance using waste polymers via dry and wet processes, J. Mater. Civ. Eng. 29 (10) (2017).

[11] M. García-Morales, P. Partal, F.J. Navarro, C. Gallegos, Effect of waste polymer addition on the rheology of modified bitumen, Fuel 85 (7-8) (2006) 936-943.

[12] D. Casey, C. McNally, A. Gibney, M.D. Gilchrist, Development of a recycled polymer modified binder for use in stone mastic asphalt, Resour. Conserv. Recycl. 52 (10) (2008) 1167-1174.

[13] Z.N. Kalantar, M.R. Karim, A. Mahrez, A review of using waste and virgin polymer in pavement, Constr. Build. Mater. 33 (2012) 55-62.

[14] M.R. Mohd Hasan, B. Colbert, Z. You, A. Jamshidi, P.A. Heiden, M.O. Hamzah, A simple treatment of electronic-waste plastics to produce asphalt binder additives with improved properties, Constr. Build. Mater. 110 (2016) 79-88.

[15] G.H. Hamedi, Effects of polymeric coating the aggregate surface on reducing moisture sensitivity of asphalt mixtures, Int. J. Civil Eng. 16 (9) (2018) 10971107.

[16] M. Arabani, Taleghani M. Yousefpour, Rutting behavior of hot mix asphalt modified by polyvinyl chloride powder, Pet. Sci. Technol. 35 (15) (2017) 16211626.

[17] M. Soltani, T.B. Moghaddam, M.R. Karim, H. Baaj, Analysis of fatigue properties of unmodified and polyethylene terephthalate modified asphalt mixtures using response surface methodology, Eng. Fail. Anal. 58 (2015) 238-248.

[18] Z. Leng, A. Sreeram, R.K. Padhan, Z. Tan, Value-added application of waste PET based additives in bituminous mixtures containing high percentage of reclaimed asphalt pavement (RAP), J. Cleaner Prod. 196 (2018) 615-625.

[19] J.D.A.A.E. Silva, J.K.G. Rodrigues, M.W. de Carvalho, L.C.D.F.L. Lucena, E.H. Cavalcante, Mechanical performance of asphalt mixtures using polymermicronized PET-modified binder, Road Mater. Pavement Des. 19 (4) (2018) 1001-1009.

[20] J.R.M. Oliveira, H.M.R.D. Silva, L.P.F. Abreu, S.R.M. Fernandes, Use of a warm mix asphalt additive to reduce the production temperatures and to improve the performance of asphalt rubber mixtures, J. Cleaner Prod. 41 (2013) 15-22.

[21] A. Subhy, D. Lo Presti, G. Airey, Rubberised bitumen manufacturing assisted by rheological measurements, Road Mater. Pavement Des. 17 (2) (2016) 290-310.

[22] S. Fernandes, H.M.R.D. Silva, Oliveira JRM. Mechanical, surface and environmental evaluation of stone mastic asphalt mixtures with advanced asphalt binders using waste materials, Road Mater. Pavement Des. (2017) 118.

[23] P. Li, X. Jiang, Z. Ding, J. Zhao, M. Shen, Analysis of viscosity and composition properties for crumb rubber modified asphalt, Constr. Build. Mater. 169 (2018) 638-647.

[24] G. Airey, M. Rahman, A.C. Collop, Crumb rubber and bitumen interaction as a function of crude source and bitumen viscosity, Road Mater. Pavement Des. 5 (4) (2004) 453-475.

[25] A. Behl, G. Sharma, G. Kumar, A sustainable approach: utilization of waste PVC in asphalting of roads, Constr. Build. Mater. 54 (2014) 113-117.

[26] S.R. Shukla, A.M. Harad, L.S. Jawale, Recycling of waste PET into useful textile auxiliaries, Waste Manage. 28 (1) (2008) 51-56.

[27] C. Giavarini, P. De Filippis, M.L. Santarelli, M. Scarsella, Production of stable polypropylene-modified bitumens, Fuel 75 (6) (1996) 681-686.

[28] J.S. Chen, T.J. Wang, C.T. Lee, Evaluation of a highly-modified asphalt binder for field performance, Constr. Build. Mater. 171 (2018) 539-545.

[29] P. Morgan, A. Mulder, The Shell Bitumen Industrial Handbook, Shell Bitumen, Chertsey (Surrey, UK), 1995.

[30] G.D. Airey, Rheological evaluation of ethylene vinyl acetate polymer modified bitumens, Constr. Build. Mater. 16 (8) (2002) 473-487.

[31] B. Sengoz, A. Topal, G. Isikyakar, Morphology and image analysis of polymer modified bitumens, Constr. Build. Mater. 23 (5) (2009) 1986-1992.

[32] G. Wen, Y. Zhang, Y. Zhang, K. Sun, Y. Fan, Rheological characterization of storage-stable SBS-modified asphalts, Polym. Test. 21 (3) (2002) 295-302.

[33] D. Lesueur, The colloidal structure of bitumen: consequences on the rheology and on the mechanisms of bitumen modification, Adv. Colloid Interface Sci. 145 (1) (2009) 42-82.

[34] A. Behnood, M. Gharehveran Modiri, Morphology, rheology, and physical properties of polymer-modified asphalt binders, Eur. Polym. J. (2018).

[35] R. Varma, H. Takeichi, J.E. Hall, Y.F. Ozawa, T. Kyu, Miscibility studies on blends of Kraton block copolymer and asphalt, Polymer 43 (17) (2002) 4667-4671.

[36] J. Kosińska, G. Boczkaj, G. Gałęzowska, J. Podwysocka, A. Przyjazny, M. Kamiński, Determination of modifier contents in polymer-modified bitumens and in samples collected from the roads using high-performance gel permeation/size-exclusion chromatography, Road Mater. Pavement Des. 17 (3) (2016) 547-562.

[37] J.S. Chen, M.-C. Liao, M.-S. Shiah, Asphalt modified by styrene-butadienestyrene triblock copolymer: morphology and model, J. Mater. Civ. Eng. (2002) 224-229.

[38] S. Kim, S.J. Lee, S. Lee, K.W. Kim, Evaluation of rut resistance of polymermodified asphalt concretes, Adv. Mater. Res. (2013) 282-288. 
[39] R. Yu, C. Fang, P. Liu, X. Liu, Y. Li, Storage stability and rheological properties of asphalt modified with waste packaging polyethylene and organic montmorillonite, Appl. Clay Sci. 104 (2015) 1-7.

[40] F.J. López-Moro, M.C. Moro, F. Hernández-Olivares, B. Witoszek-Schultz, M. Alonso-Fernández, Microscopic analysis of the interaction between crumb rubber and bitumen in asphalt mixtures using the dry process, Constr. Build. Mater. 48 (2013) 691-699.

[41] A. Jamshidi, B. Golchin, M.O. Hamzah, P. Turner, Selection of type of warm mix asphalt additive based on the rheological properties of asphalt binders, J Cleaner Prod. 100 (2015) 89-106.
[42] J. Oliver, Y. Khoo, Ensuring the quality of SBS modified binders. 25th ARB Conference - Shaping the future: Linking policy, research and outcomes. Perth, Australia, 2012.

[43] D.A. Anderson, D.W. Christensen, H.U. Bahia, R. Dongre, M.G. Sharma, Binder Characterization and Evaluation, Volume 3: Physical Characterization. SHRPA-369. Washington, DC, National Research Council, 1994.

[44] J. D’Angelo, R. Dongré, Practical use of multiple stress creep and recovery test, Transp. Res. Rec.: J. Transp. Res. Board 2126 (1) (2009) 73-82.

[45] EP. 14.03 - Pavimentação, Caracteristicas dos Materiais, In: Portugal Ed, editor Caderno de Encargos Tipo Obra. Almada: Estradas de Portugal, 2011. p. 20. 